University of Nebraska - Lincoln

DigitalCommons@University of Nebraska - Lincoln

Faculty Publications: Department of Teaching, Department of Teaching, Learning and Teacher Learning and Teacher Education

Education

2018

Teacher Twitter Chats: Gender Differences in Participants'

Contributions

Stacey L. Kerr

Mardi J. Schmeichel

Follow this and additional works at: https://digitalcommons.unl.edu/teachlearnfacpub

Part of the Curriculum and Instruction Commons, Social Media Commons, and the Teacher Education and Professional Development Commons

This Article is brought to you for free and open access by the Department of Teaching, Learning and Teacher Education at DigitalCommons@University of Nebraska - Lincoln. It has been accepted for inclusion in Faculty Publications: Department of Teaching, Learning and Teacher Education by an authorized administrator of DigitalCommons@University of Nebraska - Lincoln. 


\title{
Teacher Twitter Chats: Gender Differences in Participants' Contributions
}

\author{
Stacey L. Kerr ${ }^{1}$ and Mardi J. Schmeichel ${ }^{2}$
}

1. Department of Geography and Environmental Studies, Central Michigan University, Mt. Pleasant, Michigan, USA

2. Department of Educational Theory and Practice, University of Georgia, Athens, Georgia, USA

Corresponding author - Stacey L. Kerr, Department of Geography and Environmental Studies, Central Michigan University, Dow Science Complex, Mount Pleasant, MI 48859, USA; email stacey.kerr@cmich.edu

\begin{abstract}
Gender differences in participation were examined across four Twitter chats for social studies teachers. Analyses drawing on mixed methods revealed that while there was parity across most kinds of tweets, participants identified as men were more likely to use the examined Twitter chats to share resources, give advice, boast, promote their own blog/resource/website, and offer critique to another participants' tweet. Participants identified as women were more likely to write tweets that included positive affirmations for other chat participants. These findings suggest that there are differences in the way that women and men tend to participate in teacher Twitter chat spaces.
\end{abstract}

Keywords: Twitter, gender, in-service education, professional development

Twitter has been deemed an ideal site for do-it-yourself professional development for teachers. Research examining teacher Twitter chats (e.g., Carpenter \& Krutka, 2014, 2015; Krutka \& Carpenter, 2016; Luo, Sickel, \& Cheng, 2017; Visser, Evering, \& Barrett, 2014) position Twitter as an accessible and productive space for teachers to interact with each other in new ways. Many of these studies note that teachers interacting on Twitter value the casual, personal, and collaborative spaces they find through professional development experiences on the site. For example, Visser, Evering, and Barrett (2014) note that the 
informal professional development offered through Twitter is "appealing and valuable to educators for a variety of reasons" (p. 397). In particular, participants noted that through the professional development networks they developed on Twitter, they were able to find guidance on the particular teaching and learning issues in which they were interested. Participants could find like-minded educators through Twitter, as the platform "allowed them to easily connect with others who shared their beliefs, and [that] these connections made them feel less professionally isolated as a result" (p. 408). Further, the authors of the study noted that there were additional advantages to interacting with other teachers on Twitter, asserting that the kinds of "professional development received via Twitter have direct benefits on teachers' professional knowledge and stature" (p. 407).

Carpenter and Krutka (2015) frame the professional development experienced on Twitter in terms of its contrast with the kinds of professional development typically offered to teachers. Noting the "discouraging history" of traditional professional development experiences, these authors state that "the rise of Web 2.0 and social media sites over the last decade has inspired optimism among some educators regarding their potential to enhance various facets of the field" (p. 708). The enhancements to the professional development offered through Twitter are, according to the authors, more democratic and authentic than traditional, face-to-face professional development. They contend that "social media appears to have the potential to facilitate PD that is more participatory, grassroots and supportive of teacher's roles as professionals and intellectuals" (p. 708). In a separate study focused specifically on the Twitter spaces occupied by social studies teachers, Krutka and Carpenter (2016) describe the social studies Twitter chat (\#sschat) as an "affinity space" that addresses "topics of study appear to derive from authentic experiences and vary to meet the needs, interests, or questions of educators" (p. 51).

Overall, the research literature on teachers' Twitter chat participation provides overwhelmingly positive reports of their experiences on Twitter. These analyses reflect an optimistic orientation toward the potential of social media to provide a new and more productive form of communication and interaction. While educational researchers tout the possibilities that social media platforms can afford teachers, we point to recent work (e.g., Robson, 2016; Warf, 2017) that critiques the impetus to describe technology as an unabashed good or force for democracy and justice. As Warf reminds us, "even a casual glance at the evidence reveals that technologies can be used against people as well as for them" (2017, p. 2). As such, the same critical lens and concern for power in the ways that people interact in face-to-face groups should be applied to online interactions, a commitment reflected in the Ruiz et al. (2015) assertion that "casting new media only as channels for unprecedented forms of communication can be ingenuous, starting from the fact that much of the social interaction that happens within new media platforms follows pre-existing patterns of exchange."

The concern that the rosy glow around the affordances of digital interaction may mask inequities is found in the early analyses of the role of gender in computer-mediated communication (CMC). As Herring and Stoerger (2014) noted in their review of the research on gender in $\mathrm{CMC}$, even the earliest studies of interaction within digital spaces "problematized claims of gender-free equality in cyber space" (p. 570). These investigations revealed meaningful differences in the ways that women and men interact online. As the promotion 
of teacher Twitter chats for professional development grows more vehement, we are interested in considering how gender may play a role in the ways teachers interact with each other in these spaces.

The focus on gendered interactions between educators in Twitter chats is informed by a lack of attention to gender differences among teachers in general. The role of gender and the way it shapes teaching are addressed in educational research, but the emphasis is typically limited to the ways that profession is feminized due to the underrepresentation of men in elementary teaching positions, and the relationship between teaching and stereotypical feminized traits like nurturing. In this study, however, we focus specifically on the interactions between women and men related to the field of social studies education, a sphere of the profession that is not dominated by women. As Fitchett noted in his 2010 analysis of the National Center for Educational Statistics SASS Survey, men held $67 \%$ of all of the high school social studies teaching positions. Fitchett (2010) contended that this overrepresentation of men secondary social studies educators is significantly disproportionate when compared to the gender ratios in the other core subject areas. As such, social studies education provides a particularly ripe context for the consideration of the ways that women and men educators interact.

\section{Gender and Technology: A Brief History}

The focus of research on gender and technology has shifted significantly over time. Early concerns focused on access to the Internet, a topic that can be traced back to discussion Listserv studies conducted in the mid-1990s pointing to significant disparities between women's and men's Internet usage. Statistics now indicate that the gender gap has reversed, at least regarding social media use: a 2017 Pew report found that $66 \%$ of U.S. adult men and $72 \%$ of adult women use at least one social media platform (Pew Research Center, 2017).

Scholars' current interest in gender and technology now focuses on use and behavior and the gendering of technology (e.g., McLean, Maalsen, \& Grech, 2016), rather than access. Recent Pew Research (Pew Research Center, 2017) about social media habits indicates some gender differences in platform use. While participation on Facebook by gender has reached near parity ( $69 \%$ of women social media participants, $67 \%$ of men), there are more distinct gender differences on other platforms, like Pinterest (38\% of women participants vs. $15 \%$ men participants) and Instagram (32\% of women and $23 \%$ of men). Historically, Twitter has been the only major social media platform in which there was a slightly higher percentage of men Internet users than women. Further, Pew reported (Gottfried \& Shearer, 2016) that other discussion forums, like Reddit, had a significant imbalance of men to women participants ( $71 \%$ men users vs. $29 \%$ of women Internet users). However, in its most recent report, the Pew Research Center (2017) indicated that an equal number of women and men social media participants $-21 \%$ - use Twitter.

Further examination of the social media platforms that women and men are using, with a comprehensive consideration of the differences between the platforms dominated by women users and men users, is warranted, but beyond the scope of this study. At a minimum, however, it is important to consider why men have historically preferred the 
discussion-oriented interactions facilitated by Twitter and sites like Reddit, versus more image-powered platforms like Pinterest and Instagram. Further, we question how men's historical overrepresentation within discussion-dominated types of social media might shape the culture and norms of interactions in these digital spaces.

These concerns are framed by the knowledge that early research engagements with online technology and gender were met with optimism for their potential for "disrupting gender and bodily boundaries and the associated power hierarchies" (McLean et al., 2016, p. 38). Research dating back to the early 1990s, however, has documented that online discourse is "power-based and hierarchical" (Herring, 1993). For example, Herring's 1993 analysis of electronic discussion boards, a platform for online dialogue that served as a forerunner of current discussion-based social media, found significant differences between women's and men's participation: Men participated more, posted longer messages, and communicated in ways that Herring characterized as assertive, authoritative, and self-promoting. Women's manner of communication was described as personal and supportive. As a result of these different ways of participating, Herring noted that men were more likely to monopolize the conversation. She observed that the discussion forums she studied were "dominated by a small minority of participants who" used specific discursive strategies "to focus attention to themselves." These strategies ranged from "gratuitous displays of knowledge to forceful assertions of one's views." Overall, she concluded that these participants "dominated amount as well as manner of participation." Ten years later, in her 2003 review of gender and computer research, Herring asserted that "idealistic notions that the Internet would create a gender-blind environment and would level gender-based power asymmetries [has] limited support from the evidence about gender and the Internet since the early 1990's"' (p. 219).

More recent research demonstrates the persistence of limitations and gender differentials in one's ability to move within and through online spaces on the basis of gender. For example, there has been extensive research attention paid to young women's social media experiences and the increased anxiety, stress, and risk associated with these online platforms. Topics like sexting (e.g., Ringrose \& Harvey, 2015; Van Ouystel et al. 2017), bullying (e.g., Crooks, 2017; Dredge, Gleeson, \& de la Piedad Garcia, 2014), and self-presentation (e.g., Schmeichel, Kerr \& Linder, in press; Chua \& Chang, 2016) have been explored as sources of particular trouble for young women. These studies explore widespread practices and patterns in digital interactions in which gender plays a role. However, events like \#GamerGate highlight the kind of hostility that women encounter in some online spaces (see, for example, Dewey (2014), McLean et al. (2016), and Todd (2015) for descriptions of Gamergate, and Jane (2014) for a broader analysis of the vitriole directed at women online). Critical geography perspectives and Doreen Massey's (1993) idea of power geometries offer us a way to think about Twitter as an online space where power and gender discourses of everyday life can influence behavior, movement of ideas, and even discriminatory practices. In the discussion that follows, we outline our usage of power geometries as a theoretical framework, describe \#sschat, and detail the methods we used to collect and analyze the data. We then discuss our findings and draw on mobilities theories to make sense of the gendered interactions present in the data. 


\section{Power and Online Spaces: Theoretical Framework}

To consider gender in Twitter chats, we draw from critical feminist geographer Doreen Massey (1993), who uses the idea of power geometry to describe the power relationships between social actors within globalized spaces. While Twitter came into existence long after the time of Massey's writing, we contend that this social media site should be considered both a product and producer of globalization and the resultant increasing technological and communication interconnections. Further, we work from the assumption that online spaces such as Twitter chats are spaces worthy of geographic inquiry because, although digital, they serve as meeting places "in which trajectories of all kinds (people, ideas, commodities) collide" (Gregory et al., 2011, p. 577). The spaces of these Twitter chats may be virtual, but the actors who participate in them still mobilize ideas and interact with each other. In this space, however, ideas and interactions take the form of tweets, likes, replies, and retweets.

Mobility within a place shapes and reproduces power differentials based upon the degrees of freedom or impasse individuals face (Massey, 1993). One's ability to mobilize within both the physical and virtual world "can be a source of status and power [and] an expression of the rights to movement" (Urry, 2007, p. 9). In this vein, it is not only important to consider the ways that power and gender dynamics impact physical mobility but also the potential of these same dynamics to discipline online or virtual movement. As indicated in the introduction, educational researchers have framed Twitter as an open place in which teachers can communicate freely, but we argue that it is critical to examine the movement of ideas in this spacemore closely. The ways that participants do or do not mobilize their ideas, the ideas that are mobilized, and with whom participants interact are all connections worthy of investigation.

To make sense of the power geometries present in Twitter chats, we rely on the understanding that both technology and teaching are embedded within networks of gendered practices and processes. First, in response to the warnings about technology described thus far, we have adopted a skeptical stance on the uncritical celebration of social media. We assume that "technologies are never neutral and universally inclusive, but rather encode and generate social exclusions along multiple axes of difference" (Leszcynski \& Elwood, 2015, p. 13). Second, we build on education and gender research that has asserted that "teaching, like all occupations, has been organized, changed, and framed by gender" (Gaskell \& Mullen, 2006, p. 453). While there has not been significant attention to gender dy-

namics between women and men teachers in schools, there is a rich tradition of feminist research in organizational analyses, which provides a framework through which to posit that teachers' interactions with each other are not gender neutral. Instead, interactions are shaped by the presence of "inequality regimes" created by "loosely interrelated practices, processes, actions, and meanings that result in and maintain class, gender and racial inequalities" (Acker, 2006, p. 443).

Specifically, we draw from organizational and workplace literature (i.e., Acker, 1990, 2006; Martin, 2003; Padic \& Reskin, 2002) that describes the role of social interactions in gendering the working place and "often subtle, seemingly neutral organizational processes" 
(Ely \& Meyerson, 2000, p. 114) that lead to gender differentiation. Imported from society at large,

these social practices reflect gendered themes, in the form of masculine-feminine dichotomies, which have become deeply embedded in organizations, so deeply embedded as to appear to be gender-neutral, simply the norm. Yet, because they are rooted in men's lives and experiences, these social practices tend, in often subtle and insidious ways, to privilege men and disadvantage women, frequently compromising their ability to be maximally effective at work. (p. 142)

Feminist analysis of organizational behavior focuses not on the difference between sexed people but rather on how gender difference and inequality are manufactured through social interactions in the workplace through the repetition of interactions that come to constitute what is understood to be "normal." This research aligns with research on teaching and gender that demonstrates "teaching is historically and culturally imbued with multiple discourses and subjectivities of gender ... [which have] real consequences for male and female teachers' identity constructions, work environments, professional opportunities and possibilities" (Sabbe \& Aelterman, 2007, p. 529). Building on the understandings embedded in these frameworks, the research questions framing this study were: Are gender differences observable in participants' contributions to \#sschat? If so, what are the differences?

\section{Methods}

\#sschat is a popular Twitter chat that meets weekly to engage teachers in discussions on topics related to social studies content and methods. The chats, which have taken place since 2010, are geared at connecting educators "who aim to improve their personal, and ... collective teaching of social studies subject matter" (\#sschat.org, n.d.). The focus of these collaborations, specifically through the spaces of Twitter chats and use of the hashtag, is to engage social studies teachers "by helping to facilitate democratic collaboration where educators can challenge \& support each other to grow in their craft and, consequently, offer richer learning experiences for students" (\#sschat.org, n.d.). In particular, the organization's website indicates that \#sschat chat aims to connect educators and improve their teaching by sharing resources and ideas.

In this study, we examined four \#sschat sessions: the first chat of each month from January through April 2017. These chats were comparable in size (number of tweets and participants) and addressed a variety of social studies education topics. Across the four 1-hour chat sessions, there were 1,572 tweets with 174 unique participants. Individual chat figures are detailed in Table 1. 


\begin{tabular}{llcc}
\hline \multicolumn{2}{l}{ Table 1. \#sschat Participation } & & \\
\hline Chat Date & Chat Topic & Number of Tweets & Total Participants \\
\hline January 2, 2017 & Recharging Your Classroom & 323 & 64 \\
February 6, 2017 & Media Literacy & 409 & 110 \\
March 6, 2017 & Incorporating Current Events into Social & 479 & 74 \\
& $\quad$ Studies & & 87 \\
April 3, 2017 & Teaching about Genocide Using Testimony & 361 & \\
\hline
\end{tabular}

Using the chat archives from the four selected sessions (retrieved from Participate.com, a website that houses archives of the text generated from educational Twitter chats), the chats were organized in an Excel spreadsheet on the tweet level. Tweets were listed chronologically and included the following information: time of tweet, username, the tweet's text, whether it was a retweet, and whether it was a reply. Organizing this data on the tweet level, or, in other words, treating each tweet as an independent data segment, allowed us to impose order to an unruly data set.

After the tweets were organized in a spreadsheet, our next step was to assign a gender to each chat participant. Inferring the gender of Twitter participants is an emerging field of Internet-based research (e.g., Burger, Henderson \& Zarella, 2011; Zamal, Liu, \& Ruths, 2012). Identifying this basic demographic information about Twitter users has been pursued by both social scientists (in fields like sociolinguistics and computer science) and market researchers who seek insight into the habits of online communities. To assign gender in this study, we mimicked several different strategies described in this literature. First, we used an application from Watson Analytics that allowed us to pull Twitter profile information from the publicly available Twitter Application Programming Interface (API). The Twitter API works via a set of protocols that determine how different software applications may interact with publically available data (i.e., the tweets from the examined Twitter chats). The flow of data between Twitter and the Watson Analytics platform is restricted, but we were able to use Watson Analytics to access the self-reported gender of approximately $60 \%$ of the individual participants in these chats. For the participants whose profile information we could not access through this method, we drew from strategies described in inference literature to assign gender. These strategies included looking at users' names and assigning gender by their appearance on lists of common U.S. names by gender (Liu \& Ruths, 2013). Additionally, we examined users' Twitter bios to look for gendered pronoun use and the presence of words commonly associated with women's and men's gender assignments (e.g., husband, mother).

Assigning gender through a process like this is problematic, but it is an increasingly common issue in social media research in which there is limited information available about the participants who have generated publically available data. We assert that while the process we used to "assign" gender to the chat participants is messy and sure to be flawed in terms of the real-life complexity of the participants' gender experiences, to ignore gender altogether would also be a problematic choice. As such, we decided to move forward with these "messy" methodological strategies for inferring gender. Across the four chats, we labeled 69 participants as women, and 86 participants as men; 34 participants 
were not assigned gender because the user tweeted from a Twitter account associated with a business or organization (e.g., iCivics).

We used mixed methods to analyze this data. First, we drew from qualitative methodologies to analyze the chats. Both authors read each chat two times, tweet by tweet, to become familiar with the content and tenor of each discussion. As we read, we noted patterns, commonalities, and inconsistencies at the chat level as well as the individual tweet level. Relevant and interesting data excerpts were tagged, and we used these tags to develop an initial set of codes to describe the tweets types. In further rounds of the coding process, both researchers read and reviewed all tagged tweets from the chat archives and discussed emerging and overlapping codes across the data.

Through several rounds of simplifying and distilling our code list, we determined that tweets across the chats could be organized into six different type categories. The type codes assigned to these tweets ranged from "Resource Sharing" to "Question Asked." Upon identifying these six type codes, we reviewed the data set again to assign one of these codes to each tweet and used interrater reliability checks (Glesne, 1992) to verify the consistent use and application of codes to the data. After this stage, we determined that some tweets could be categorized using another level of typology. We thus added codes that described the tone of the tweet, such as "Authoritative," "Critique," and "Affirmation" (see Appendix for complete list of type and tone codes).

Once we had coded all 1,572 tweets for both type and tone, we turned to quantitative analysis to perform a series of statistical analyses.We began by removing all tweets sent from a chat moderator. The moderators make up a significant part of each chat by asking questions of participants and responding to individual participant responses. We believe this high number of tweets sent from the moderators $(n=219)$ reflects a form of participation that is significantly different from the tweets and interactions of regular chat participants. Analyzing moderator facilitation and participation in teacher twitter stats is a topic worthy of further investigation but not the focus of this particular study. The statistical results described in the findings are thus an analysis of the remaining 1,353 tweets sent from Twitter chat participants we labeled as women and men.

While there was some variation among chats in gender parity, the overall results indicate an almost equal participation in average tweets among women and men (Table 2).

Table 2. Gender Composition of Analyzed \#sschats

\begin{tabular}{lccc}
\hline Gender & Number of Participants & Number of Tweets & Average Tweets per Participant \\
\hline Men & 86 & 696 & 8 \\
Women & 69 & 657 & 9.5 \\
\hline
\end{tabular}

To conduct a more thorough analysis of the frequency of tweet types by gender, we used a series of mean comparison tests ( $t$-tests). The $t$-tests allow researchers to understand whether there are statistical differences between two populations. In our study, this means that the $t$-tests helped us understand whether the types and tones of tweets sent by women and by men were statistically different from each other.We also investigated the likelihood of types and tone of tweets sent, regardless of gender. 


\section{Results}

Our analysis began by considering the categories of tweets most commonly produced within the data set. Among all participants, the most common type of tweet in the 1,353 tweets was the type coded as engagement (49\%). Tweets coded as engagement type were characterized by the use of the "reply" function, which tagged another user, or the specific use of another participant's username in a tweet. The other most common tweet types were those that answered a question posed by the moderator (39\%) or shared a resource $(36 \%)$.

In our second round of analysis, each tweet was also coded for its tone, such as "descriptive," "directive," and "critique." In this analysis, our intent was not to interpret the motivation of the tweet authors, but rather to consider what the tweets themselves produced. Rose (1999) captured the potential of this strategy when he argued that

power relations and ethical imperatives put in play ... need to be examined in their own terms. Against interpretation, then, I advocate superficiality, an empiricism of the surface, of identifying the differences in what is said, how it is said, and what allows it to be said and to have an effectivity. (p. 57)

The tone that appeared most frequently in the data set was "directive" (36\%). The directive code was applied to tweets that expressed beliefs, ideas, and suggestions assertively. These kinds of tweets were characterized by the unmediated way in which participants directed others to think about particular ideas or adopt a particular strategy. The following tweet from one user is an example of a directive contribution: "One thing we need to avoid is only using one source for teaching current events \#sschat \#1 perspectiveisonly1" (February 6 , 2017). Like the other tweets coded "directive," this tweet definitively instructs other chat participants about what a teacher should or should not do. The use of the phrase "we need to" contributes to the authoritative tone. Directive tweets were prescriptive and instructive responses, interactions, and advice that communicated a firm and assured stance on the topic at hand.

Of all tweets, $26 \%$ were coded as "descriptive." These tweets were coded as such because they included some description of participants' particular teaching contexts or experiences, like this January 2, 2017, tweet from another user: "This quarter, I'm focused on student-driven research, communication of that research, and student discussion. \#sschat." Through the inclusion of some personal context or experience, descriptive tweets offer at least some limited insights into specific contexts.

Another commonly coded tweet among the data were those that were affirming (21\%). These tweets included a positive acknowledgment or grateful recognition for another's idea, comments of solidarity or empathy, and commentary on the perceived productivity of being a participant in \#sschat. Many of these tweets directed the positive affirmation toward \#sschat itself, such as this tweet: "I'm going to make a special effort to attend every \#sschat this semester. You guys give me so much inspiration" (January 2, 2017). Another type of tweet found in the data was labeled as "Promotion." Tweeters posting these comments specifically referred other chat participants to a resource of their own creation. For example, in the following tweet, the user references and provides a link to a lesson on his 
website: "I made a lesson comparing a His[tory] channel show to an actual documentary. Ss were shocked https://t.co/y9xvL6UanD" (February 6, 2017).

As one may infer, the tweet type and tone categories were not mutually exclusive: One tweet could be coded into multiple categories. For example, in the February 2017 chat on media literacy, one user tweeted the following about the importance of source material and point of view in reply to another participant's tweet: "Currently working on this w/ russia hacking story. I found sites and having Ss use CRAAP test https://t.co/Dpf2yhEgwD \#sschat" (February 6, 2017). In our data set, this tweet received three different codes: "engagement" because it was in reply to another participant's tweet; "resource sharing" for its link to a PDF containing evaluation criteria for media sources; and "descriptive" as the tweet described something this participant was doing with students (denoted as Ss in the tweet) in their classroom practice.

Once we had identified the most common types of tweets among all participants, we tested the statistical differences in tweets sent by women and men. Table 3 illustrates the series of mean comparison tests for gender differences observed in tweet type and tone categories. Across our 15 code categories, including both type and tone, there was no statistically significant difference between men and women in nine of the categories. This means that not one group of participants dominated responses in one way or another across the majority of codes used to analyze the data.

Table 3. Mean Comparison Tests for Gender Differences by Tweet Type and Tone

\begin{tabular}{lccc}
\hline & Tweets Sent from Men & Tweets Sent from Women & Difference \\
\hline Resource sharing & 0.16 & 0.10 & $-0.06^{* * *}$ \\
& $(0.01)$ & $(0.02)$ & $(0.01)$ \\
Advice & 0.05 & 0.03 & $-0.03^{* * *}$ \\
& $(0.01)$ & $(0.01)$ & $(0.01)$ \\
Boasting & 0.02 & 0.003 & $-0.19^{* * *}$ \\
& $(0.006)$ & $(0.002)$ & $(0.006)$ \\
Promotion & 0.06 & 0.02 & $-0.04^{* * *}$ \\
& $(0.009)$ & $(0.006)$ & $(0.01)$ \\
Critique & 0.09 & 0.04 & $-0.05^{* * *}$ \\
& $(0.11)$ & $(0.008)$ & $(0.014)$ \\
Affirmation & 0.14 & 0.20 & 0.06 \\
& $(0.16)$ & $(0.02)$ & $(0.16)$ \\
$n$
\end{tabular}

Note: Standard errors are given in parentheses.

$* * * 1 \%$ significance level.

In one type category and five tone categories, however, the types of tweets sent by men versus women were statistically different. In particular, there were significantly more tweets from men that were coded by type as "resource sharing." Tweets coded as resource sharing included a reference or link to a specific teaching or content resource, like this tweet: "I enjoy scanning the daily front pages at https://t.co/ogn1HeJNOL. Look for articles that are interesting and inspire debate" (March 6, 2017). Tweets sent by men account for 
$16 \%$ (denoted as 0.16 in Table 3), versus $10 \%$ for tweets posted by women. This $6 \%$ difference is statistically significant at the $1 \%$ confidence level.

For the tone categories, men sent significantly more tweets giving "advice" (5\% of men's tweets), "boasting" about one's own successes and experiences, examples of which included announcing conferences attended/presented at and educational fellowships received ( $2 \%$ of all men's tweets), "promoting" one's own blog/resource/website ( $6 \%$ of all men's tweets), and offering "critique" (9\% of all men's tweets). These tweet differences, outlined in Table 3, were all significant at the 1\% confidence level, and represent statistically significant differences in type and tone of the 1,353 analyzed tweets.

There was also a statistically significant difference in tweets we labeled as "affirming," a tone code described earlier. Affirming tweets made up $20 \%$ of all tweets sent by women, versus $14 \%$ of men's tweets. This difference of approximately $6 \%$ was also significant at the $1 \%$ level.

\section{Discussion}

Men and women appear to be equally active within \#sschat Twitter chats in terms of themost basic and easily identified gauges of chat participation: total numbers of tweets and average tweets per participant. At a glance, then, one might assume that gender plays little to no role in participants' interactions in the chat. However, the analysis of the data described here indicates that upon a closer examination of the types of tweets produced and the tone of those tweets, there are some differences in the ways that women and men participate in this space. As Massey (1993) illustrates with the idea of power geometries, simply because different groups are engaged in similar amounts of movement does not mean that the different groups experience the same degree of freedom in that movement. In the case of the analyzed chats, men sent significantly more tweets that shared resources; boasted about professional and personal achievements; promoted a blog, website, or selfcreated resource; offered critique; and gave advice. The analyzed tweets in this study are helpful in illustrating that while many forms of participation in these spaces were not differentiated on the basis of gender, aspects of women's and men's participation did not possess the same qualities.

We draw upon Massey (1993) once more to address the difference between quantity and quality of movement. While two groups, in this case, men and women participants in Twitter chats, may move their ideas at equally frequent intervals, power differentials impact the freedom experienced in mobility within the chat spaces. Specifically, the statistical differences point to the way that men are subtly encouraged and affirmed to send tweets that share resources, boast about successes and experiences, critique, promote, and give advice, while women are freer to affirm other participants. The distinctions between these types of contributions to the chat can be illuminated by considering Massey's idea that "different social groups have distinct relationships to this anyway differentiated mobility: some people are more in charge of it than others; some initiate flows and movement, others don't; some are more on the receiving-end of it than others; some are effectively imprisoned by it" (p. 61). Specifically, we want to consider how the types of tweets that were 
more likely to be produced by men than women give us some insight into the relationship between the flow of ideas and gender power geometries operating in \#sschats.

Ely and Meyerson (2000) describe the tendency in Western cultures to ascribe traits of individualism to men and masculinity and traits of collectivism to women and femininity. They assert that these images "portray competence as heroic independence and collaborative and development activities as tangential-nice, but not necessary - the other effective functioning of the organization" (p. 124). They go on to argue that "social practices that support and sustain individual heroism as the most effect strategies for getting ahead ... [but] collaborations, team-work, capacity-building, smoothing difficulties, and developing others is often invisible work" (p. 124). We used these ideas to frame our understanding of the gender differences in this set of tweets. Sharing, boasting, critiquing, promoting, or advice-giving are discursive strategies that can be seen as sustaining the kind of individualism that Ely and Meyerson assert are ascribed to men and masculinity. The type of tweets women were more likely to send affirmed others and can be interpreted as contributing to the kind of invisible work of capacity building and support of the collective. In this way, we can trace the gender dynamics in real-life spaces described by Ely and Meyerson within interactions in online spaces as well.

While we assert that these tracings of power differentials are present, the data do not indicate the perceived value of the different type and tone of tweets. Given the available information, we cannot say whether or not the type and tone of tweets sent by men and women were found to be more useful, productive, or engaging by other participants within the space of Twitter chats. However, we can use the statistically significant differences as an indication that there appears to be a relationship in \#sschat Twitter chats between the ways that people tweet and their gender. This consideration of who gets to be authoritative, argumentative, and knowledgeable within Twitter chats is important in coming to understand the differential valuation of social practices that "create systematic distinctions between men and women depending in part on their ability and willingness to conform to the dominant cultural these practices uphold" (Ely \& Meyerson, 2000, p. 117). As such, coming to an understanding of gender dynamics in the spaces of \#sschat must attend to considering who moves and who does not, and concerns about how power flows as a result of that movement.

\section{Limitations and Conclusions}

There are several limitations in our study that warrant acknowledgment. First, the analysis included only four \#sschat sessions. While the 1,572 tweets generated through these chats is not an insubstantial number, any inferences about the culture and norms present in \#sschat must be circumscribed. As a community that chats almost every week of the year, our limited data set does not stand in for a representative sample of chat archives as a whole. The use of a larger data set would be required to come to any generalized conclusions about gender dynamics in these spaces. Of particular interest and value would be the investigation into whether different gender dynamics exist when specific subjects, grade levels, or topics are the focus of the chat. 
Second, we acknowledge that the style and stances an individual uses to enact gender are wide and varied. Further, it is important to acknowledge that gender interacts with other subjectivities in ways that shape how individuals participate in discussion and interact with others. How gendering occurs, with which particular men and women are most likely to be affected, "varies systematically as a function of other aspects of identity, such as race, ethnicity, social class, and sexual identity" (Ely \& Meyerson, 2000, p. 142).

Finally, we do not know the extent or degree to which users are aware of the gender of the chat participants with whom they are engaging. While the gender signals of some usernames are clear (e.g., @MrsThomas, @MrMarvin), in many cases gender is not signaled through a name (e.g., @edtechtoolsforall). The same methods we used to label gender are likely part of normal use for many chat participants (i.e., reviewing bios and making assumptions based on commonly gendered name use). It is also likely that many participants may view other participants as relatively anonymous actors. As such, we cannot determine the extent to which gender was an explicit factor in the ways individuals behaved in these spaces. This limits any claims we can make about the causes that contributed to the gender differences we identified.

However, our interest is much more in thinking about the subtle and normalized (Ely \& Meyerson, 2000; McLean et al., 2016) ways of being and interacting that shape teachers' gendered interactions with each other in this digital space. The patterns we have identified in this study show a significant overlap in the most repeated types of \#sschat interactions, but a clear distinction between women's and men's behavior in some unique types of tweets. We argue that this demonstrates that something gendered is going on these spaces. In particular, how someone moves and the level of control and freedom the person has in that movement "both reflect and reinforce power" (Massey, 1993, p. 62). Further investigation of more chats and the tweets that populate them is thus required to help look beyond the general parity found in rates of participation among men and women, and to also consider the ways that power may become territorialized through repeated patterns of tweet types and tone. Considering the territorialization of power within the space of \#sschat Twitter chats is important because the power geometries that are created and reinforced in specific spaces construct boundaries that can create "ideas of inclusions and exclusion" (Gregory et al., 2011, p. 576, emphasis added). Considering who does or does not feel welcome within a space based at least in part upon gender is necessary as the popularization of Twitter chats for educators continues to increase.

\section{References}

\#sschat.org. (n.d.). About us. Retrieved from https://sschat.org/about-us

Acker, J. (1990). Hierarchies, jobs, bodies: A theory of gendered organizations. Gender E Society, 4(2), 139-158. doi:10.1177/089124390004002002

Acker, J. (2006). Inequality regimes: Gender, class, and race in organizations. Gender E Society, 20(4), 441-464.

Bamman, D., Eisenstein, J., \& Schnoebelen, T. (2014). Gender identity and lexical variation in social media. Journal of Sociolinguistics, 18(2), 135-160. doi:10.1111/josl.12080 
Burger, J. D., Henderson, J., Kim, G., \& Zarrella, G. (2011, July). Discriminating gender on Twitter. In Proceedings of the conference on empirical methods in natural language processing (pp. 1301-1309). Association for Computational Linguistics.

Carpenter, J. P., \& Krutka, D. G. (2015). Engagement through microblogging: Educator professional development via Twitter. Professional Development in Education, 41(4), 707-728. doi:10.1080/19415257 .2014 .939294

Carpenter, J. P., \& Krutka, D. G. (2014). How and why educators use Twitter: A survey of the field. Journal of Research on Technology in Education, 46(4), 414-434. Retrieved from http://cmich .idm.oclc.org/login?url $\rightarrow$ https://search.proquest.com/docview/1632517880?accountid=10181. doi: 10.1080/15391523.2014.925701

Chua, T. H. H., \& Chang, L. (2016). Follow me and like my beautiful selfies: Singapore teenage girls' engagement in self-presentation and peer comparison on social media. Computers in Human Behavior, 55, 190-197. doi:10.1016/j. chb.2015.09.011

Crooks, H. R. (2017). An intersectional feminist review of the literature on gendered cyberbullying: Digital girls. Jeunesse: Young People, Texts, Cultures, 8(2), 62-88. doi:10.1353/jeu.2017.0003

Cunha, E., Magno, G., Goncalves, M. A., Cambraia, C., \& Almeida, V. (2014). He votes or she votes? Female and male discursive strategies in Twitter political hashtags. PLoS ONE, 9(1). doi:10.1371/ journal.pone.0087041

Dewey, C. (2014, 14 October). The only guide to GamerGate you will ever need. Washington Post. Retrieved from https:/www.washingtonpost.com/news/the-intersect/wp/2014/10/14/the-only-guideto-gamergate-you-will-ever-need-to-read/?utm_term=.8766cf3584d2

Dredge, R., Gleeson, J. F., \& de la Piedad Garcia, X. (2014). Risk factors associated with impact severity of cyberbullying victimization: A qualitative study of adolescent online social networking. Cyberpsychology, Behavior, and Social Networking, 17(5), 287-291. doi:10.1089/cyber.2013.0541

Ely, R. J., \& Meyerson, D. E. (2000). Theories of gender in organizations: A new approach to organizational analysis and change. Research in Organizational Behavior, 22, 103-151. doi:10.1016/S01913085(00)22004-2

Fitchett, P. (2010). A profile of twenty-first-century secondary social studies teachers. Journal of Social Studies Research, 31(2), 229-265.

Gaskell, J., \& Mullen, A. (2006). Women in teaching: Participation, power and possibility. In C. Skelton, B. Francis, \& L. Smulyan (Eds.), The SAGE handbook of gender and education (pp. 453-468). Washington, DC: Sage.

Glesne, C. (1992). Becoming qualitative researchers: An introduction. New York, NY: Pearson.

Gottfried, J., \& Shearer, E. (2016). News use across social media platforms 2016: Appendix A: 2013 and 2016 trends. Pew Research Center. Retrieved from http://www.journalism.org/2016/05/26/social-mediaand-news-2016-appendix-a-2013-and-2016-trends/

Gregory, D., Johnston, R., Pratt, G., Watts, M., \& Whatmore, S. (Eds.). (2011). The dictionary of human geography. Hoboken, NJ: John Wiley \& Sons.

Herring, S. C. (1993). Gender and democracy in computer-mediated communication. Electronic Journal of Communication, 3(2). Retrieved from http://www.cios.org/EJCPUBLIC/003/2/00328.HTML

Herring, S. C. (2003). Gender and power in online communication. In J. Holmes \& M. Meyerhoff (Eds.), The handbook of language and gender (pp. 202-228). Oxford, UK: Blackwell Publishers.

Herring, S. C., \& Stoerger, S. (2014). Gender and (a)nonymity in computer-mediated communication. In S. Ehrlich, M. Meyerhoff, \& J. Holmes (Eds.), The handbook of language, gender, and sexuality (2nd ed., ppp. 567-586). Hoboken, NJ: John Wiley \& Sons. 
Holberg, K., \& Hellsten, I. (2015). Gender differences in climate change communication on Twitter. Internet Research, 25(5), 811-828. doi:10.1108/IntR-07-2014-0179

Jane, E. (2014). "Your a ugly, whorish, slut": Understanding e-bile. Feminist Media Studies, 14(4), 531546.

Krutka, D., \& Carpenter, J. (2016). Participatory learning through social media: How and why social studies educators use Twitter. Contemporary Issues in Technology and Teacher Education, 16(1), 3859.

Leszczynski, A., \& Elwood, S. (2015). Feminist geographies of new spatial media. Canadian Geographer/Le Géographe canadien, 59(1), 12-28. doi:10.1111/cag.12093

Liu, W., \& Ruths, D. (2013, March). What's in a name? Using first names as features for gender inference in Twitter. In AAAI spring symposium: Analyzing microtext 13(1), 10-16.

Luo, T., Sickel, J., \& Cheng, L. (2017). Preservice teachers' participation and perceptions of Twitter live chats as personal learning networks. TechTrends, 61(3), 226-235. doi:10.1007/s11528-016-0137-1

Markham, A., \& Buchanan, E. (2012). Ethical decision-making and internet research. Association of Internet Researchers. Retrieved from https://aoir.org/reports/ethics2.pdf

Martin, P. Y. (2003). "Said and done" versus "saying and doing": Gendering practices, practicing gender at work. Gender E Society, 17(3), 342-366. doi:10.1177/0891243203017003002

Massey, D. (1993). Power-geometry and a progressive sense of place. In Mapping the futures: Local cultures, global change, J. Bird, B. Curtis,T. Putnam, G. Robertson, \& L. Tickner (Eds.), (pp. 59-69). London: Routledge.

McLean, J., Maalsen, S., \& Grech, A. (2016). Learning about feminism in digital spaces: Online methodologies and participatory mapping. Australian Geographer, 47(2), 157-177. doi:10.1080/00049182 .2016.1138842

Pew Research Center. (2016) News use across social media platforms 2016. Retrieved from http://www .journalism.org/2016/05/26/social-media-and-news-2016-appendix-a-2013-and-2016-trends/

Pew Research Center (2017). Social media fact sheet. Retrieved from http://www.pewinternet.org/factsheet/social-media/

Padavic, I., \& Reskin, B. F. (2002). Women and men at work. Thousand Oaks, CA: Pine Forge Press.

Ringrose, J., \& Harvey, L. (2015). Boobs, back-off, six packs and bits: Mediated body parts, gendered reward, and sexual shame in teens' sexting images. Continuum, 29(2), 205-217. doi:10.1080/10304312 .2015 .1022952

Robson, J. (2016). Engagement in structured social space: an investigation of teachers' online peerto-peer interaction, Learning, Media and Technology, 41(1), 119-139. doi:10.1080/17439884.2015 .1102743

Rose, N. (1999). Powers of freedom: Reframing political thought. Cambridge, UK: Cambridge University Press.

Ruiz, M., Herms, C., Masserano, E., Miotto, L., Patruss, K., Gomez, I. V., \& Wielowiejski, P. (2015, August 17). \#Neoliberation: The self in the era of new media [Weblog post]. Retrieved from http://www .theoryculturesociety.org/neoliberation -the-self-in-the-era-of-new-media

Sabbe, E., \& Aelterman, A. (2007). Gender in teaching: A literature review. Teachers and Teaching: Theory and Practice, 13(5), 521-538. doi:10.1080/13540600701561729

Schmeichel, M., Kerr, S., \& Linder, C. (in press). Selfies as postfeminist pedagogy: The production of traditional femininity in the US South. Gender and Education. doi:10.1080/09540253.2017.1411890

Todd, C. (2015). Commentary: GamerGate and resistance to the diversification of gaming culture. Women's Studies Journal, 29(1), 64-67. 
Urry, J. (2007). Mobilities. Cambridge, UK: Polity Press.

Van Ouytsel, J., Van Gool, E., Walrave, M., Ponnet, K., \& Peeters, E. (2017). Sexting: Adolescents' perceptions of the applications used for, motives for, and consequences of sexting. Journal of Youth Studies, 20(4), 446-470.

Visser, R., Evering, L. C., \& Barrett, D. (2014). \#Twitterforteachers: The implications of Twitter as a self-directed professional development tool. Journal of Research on Technology Education, 46(4), 396-413. doi:10.1080/15391523.2014.925694

Warf, B. (2017) Introduction. In B. Warf (Ed.), Handbook on geographies of technology (pp. 1-16). Northhampton, MA: Edward Elgar.

Zamal, F., Liu, W., \& Ruths, D. (2012). Homophily and latent attribute inference: Inferring latent attributes of Twitter users from neighbors. Proceedings of the 6th International AAI Conference on Weblogs and Social Media, 270, 387-390.

\begin{tabular}{ll}
\hline Appendix. Tweet Types and Tones \\
\hline Type & Resource sharing \\
& Resource seeking \\
& Engagement \\
& Greeting \\
& Question asked \\
& Compliment \\
& Advice \\
Tone & Affirmation \\
& Boast \\
& Challenge \\
& Commentary \\
& Critique \\
& Directive \\
& Descriptive \\
& Promotion \\
\hline
\end{tabular}

\section{Author Notes}

Stacey Kerr (http://orcid.org/0000-0003-3044-4705) is an assistant professor in the Department of Geography and Environmental Studies at Central Michigan University. Her research interests include geography education and issues of gender and space.

Mardi Schmeichel (http://orcid.org/0000-0001-7765-7076) is an associate professor in the Department of Educational Theory and Practice at the University of Georgia. Her research interests include social media use, neoliberalism, and social studies education. 